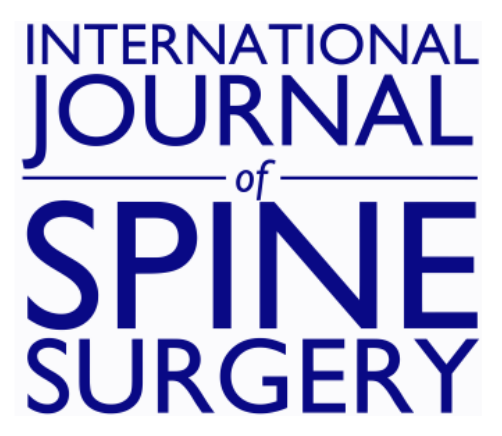

\title{
Long-Term Clinical Outcomes With the Activ-L Lumbar Arthroplasty System
}

\author{
JEAN-PAUL BRYANT, JOHN PAUL G. KOLCUN, G. DAMIAN BRUSKO, MICHAEL Y. \\ WANG and ROLANDO GARCIA, JR
}

Int J Spine Surg 2020, 14 (5) 731-735

doi: https://doi.org/10.14444/7105

http://ijssurgery.com/content/14/5/731

This information is current as of April 26, 2023.

Email Alerts Receive free email-alerts when new articles cite this article. Sign up at: http://ijssurgery.com/alerts 


\title{
Long-Term Clinical Outcomes With the Activ-L Lumbar Arthroplasty System
}

\author{
JEAN-PAUL BRYANT, MSc, ${ }^{1}$ JOHN PAUL G. KOLCUN, MD ${ }^{2}$ G. DAMIAN BRUSKO, MD, ${ }^{1}$ MICHAEL Y. \\ WANG, MD, ${ }^{1}$ ROLANDO GARCIA, JR, MD ${ }^{3}$ \\ ${ }^{1}$ Department of Neurological Surgery, University of Miami Miller School of Medicine, Miami, Florida, ${ }^{2}$ Department of Neurological Surgery, Rush University \\ Medical Center, Chicago, Illinois, ${ }^{3}$ Orthopedic Care Center, Aventura, Florida
}

\begin{abstract}
Background: Low back pain (LBP) due to degenerative disc disease (DDD) is the most common occupational disorder worldwide. Lumbar total disc replacement (LTDR) has provided an alternative to rigid fusion to relieve pain with less motion restriction. We present clinical results with long-term follow-up from a single-center, single-surgeon series of patients treated with the Activ-L artificial disc.

Methods: Thirty-three patients with symptomatic single-level DDD who failed nonsurgical therapy for a minimum of 6 months underwent single-level arthroplasty with the Activ-L system between 2007 and 2012. Demographic, preoperative, and postoperative data were collected prospectively. Clinical factors reviewed included occupational status, sensory deficits, functional status determined by Oswestry Disability Index (ODI), back pain, leg pain, pain medication consumption, and radiographic imaging.

Results: Average age at surgery was $38.0 \pm 7.8$ years, and the majority of patients were male $(60.6 \%)$. Average follow-up was $2.7 \pm 1.7$ years. Average ODI at preoperative baseline was $54.6 \pm 13.5$, with scores significantly improved at 6 weeks $(28.6 \pm 17.4, P<.0001), 3$ months $(24.1 \pm 16.8, P<.0001), 6$ months $(22.3 \pm 16.3, P<.0001), 1$ year $(18.8 \pm 15.3, P<.0001)$, and final follow-up $(15.6 \pm 16.4, P<.0001)$. Most patients $(87.8 \%)$ reported pain medication usage within 14 days of baseline evaluation, with consumption decreasing significantly at 1 -year $(34.5 \%, P$ $<.0001)$ and long-term follow-up $(21.2 \%, P<.0001)$. One patient experienced mild unilateral graft subsidence at 1 year, which remained stable on radiographs at 5 years. None of the prostheses required revision surgery.

Conclusions: The Activ-L disc replacement system is safe and effective for treating single-level lumbar DDD. Patients reported significant improvement in functional outcomes and decreases in pain medication consumption. Further investigation of the Activ-L system in larger populations is warranted.

Clinical Relevance: LBP is a common cause of disability worldwide, and better treatment options are needed to improve outcomes, including pain and mobility. Spine surgeons may choose the Activ-L disc replacement as a safe and effective treatment for LBP caused by single-level lumbar DDD.
\end{abstract}

Total Disc Replacement

Keywords: low back pain (LBP), degenerative disc disease (DDD), lumbar total disc replacement (LTDR), Activ-L artificial disc, arthroplasty

\section{INTRODUCTION}

Low back pain (LBP) due to degenerative disc disease (DDD) represents one of the most common causes of disability in adult patients. ${ }^{1}$ Previous literature has named LBP as the most common occupational disorder worldwide, with a global prevalence of $84 \%$ among workers and an incidence of 139 per 100,000 person-years among the general population in the United States. ${ }^{2-5}$ For many years, surgical management (including decompression and fusion procedures) or conservative medical treatment were the only options for treating LBP due to DDD. However, the advent of lumbar total disc replacement (LTDR) provided spine surgeons with an alternative to rigid fusion to relieve pain with less motion restriction. Although LTDR has proven to be a viable option, its utility remains controversial due to limited, albeit growing, clinical investigations. $^{2,6}$

A successful postoperative course following LTDR is largely dependent on the efficacy of the lumbar artificial disc that replaces the diseased intervertebral segment. Additionally, careful diagnostic evaluation to establish the pain generator is vital to successful replacement of the pathologic segment. LBP can be influenced by a myriad of anatomic sources and psychosomatic factors. Thus, 
Table 1. Patient demographics.

\begin{tabular}{lc}
\hline Parameter & Value, n (\%) \\
\hline Male & $20(60.6)$ \\
Female & $13(39.4)$ \\
Hispanic, Latino, or Spanish origin & $15(45.5)$ \\
Black or African American & $7(21.1)$ \\
White & $11(33.3)$ \\
\hline
\end{tabular}

detailed occupational history, substance use or abuse, and psychosocial history must be considered. Once DDD is suspected as the source for the LBP, imaging studies such as magnetic resonance imaging and computed tomography should be used in tandem with the patient's clinical presentation for diagnosis. ${ }^{7}$ Precise evaluation of the pain generator avoids misdiagnosis and guides subsequent treatment decisions, which ultimately may result in LTDR.

The first lumbar artificial disc was implanted in 1960 and, since that time, multiple replacement devices have been brought to market, including the ProDisc I, ProDisc II (Synthes Spine, West Chester Pennsylvania), and SB Charite (DePuy Spine, Raynham, Massachusetts). ${ }^{6}$ In 2007, the Activ-L lumbar disc replacement system (Aesculap Implant Systems, Center Valley, Pennsylvania) underwent clinical testing, adding a novel device to the increasing number of lumbar disc prostheses. The Activ-L device is a weight-bearing implant comprising 2 titanium endplates and 1 inlay made from polyethylene. ${ }^{8}$ The device is indicated for patients with symptomatic single-level DDD who have failed a minimum of 6 months of conservative nonsurgical treatment. In this study, we present clinical results with long-term follow-up from a single-center, single-surgeon series of patients treated with the Activ-L artificial disc.

\section{METHODS}

Patients with symptomatic single-level DDD who failed nonsurgical therapy for a minimum of 6 months were treated by LTDR with the Activ-L system between 2007 and 2012. Thirty-three patients underwent single-level arthroplasty with the Activ-L system. Patients were subsequently followed for clinical and radiologic outcomes. Demographic, preoperative, and postoperative data were collected prospectively. Preoperative and postoperative clinical factors collected included occupational status, sensory deficits, functional status as determined by Oswestry Disability Index (ODI), ${ }^{9}$ back pain (BP),

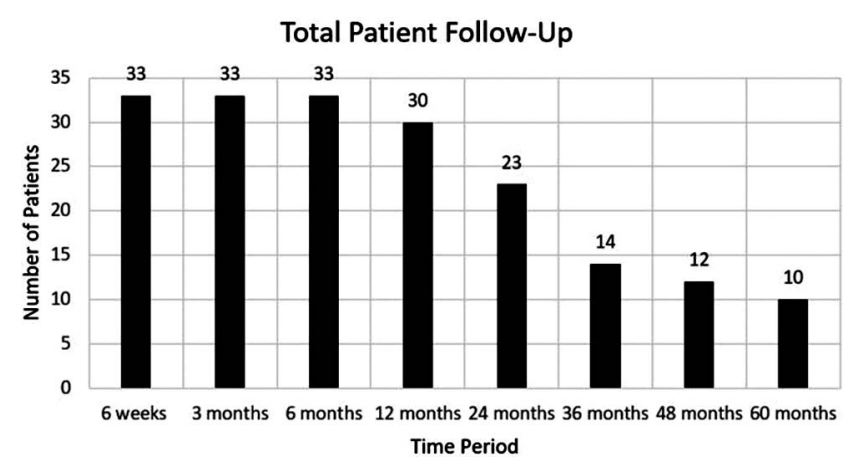

Figure 1. Number of patients at each follow-up time point.

leg pain (LP), and pain medication consumption. Comparison of preoperative and postoperative clinical factors were completed by $t$ test and $\chi^{2}$ analyses. A $P$ value $<.05$ was considered significant.

\section{RESULTS}

The average age at surgery was $38.0 \pm 7.8$ years. A majority of patients were male $(60.6 \%)$. The average long-term follow-up was $2.7 \pm 1.7$ years (range, 6 months -5 years). Patient details are given in Table 1. The specific number of patients followed at each time point is detailed in Figure 1. The average ODI at preoperative baseline was 54.6 \pm 13.5. Patients' ODI scores significantly improved at 6 weeks $(28.6 \pm 17.4, P<.0001), 3$ months $(24.1 \pm$ 16.8, $P<.0001), 6$ months $(22.3 \pm 16.3, P<.0001)$, 1 year $(18.8 \pm 15.3, P<.0001)$, and final follow-up $(15.6 \pm 16.4, P<.0001)$ (Figure 2$)$. At baseline, $33 \%$ of patients were unable to work due to their back injury. At 1-year and final follow-up, all patients were able to work with either light duty restrictions or with no lifting restrictions. Radiologic follow-up demonstrated that 1 patient had mild unilateral graft subsidence at 1 year, which re-

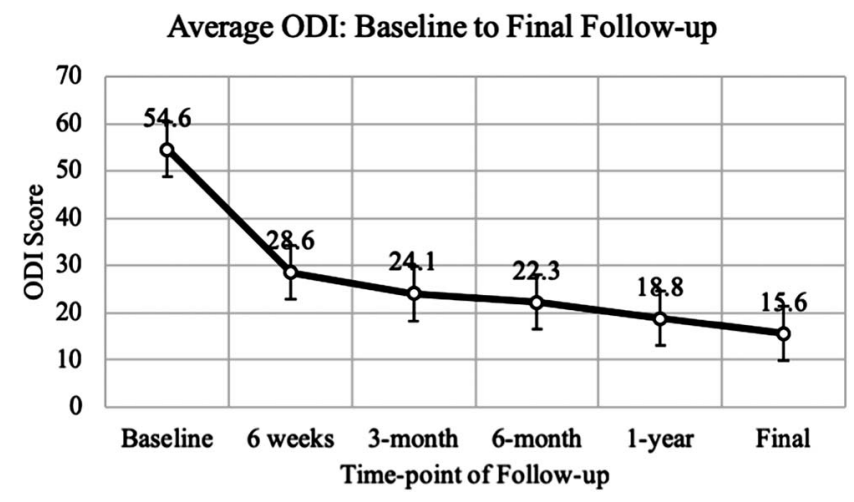

Figure 2. ODI from initial evaluation at baseline to final long-term follow-up. 


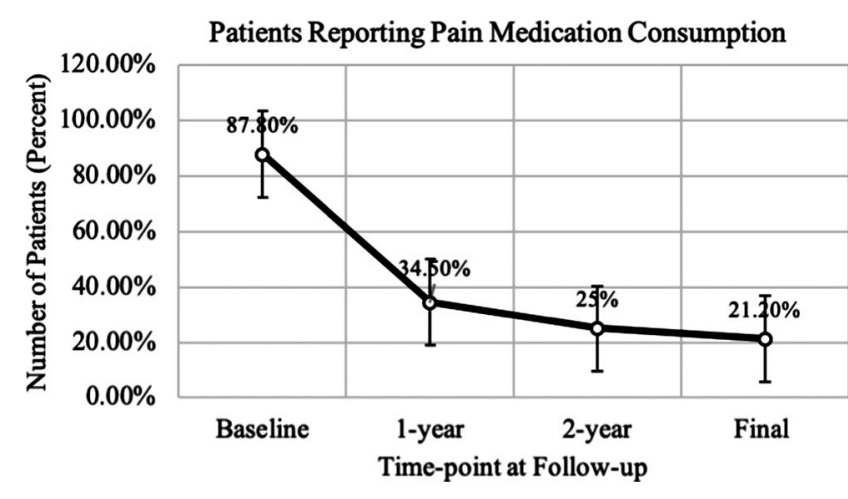

Figure 3. Percent of patients reporting pain medication consumption within the last 14 days from baseline to final long-term follow-up.

mained stable on serial $x$-ray out to 5 years. The remaining patients all had follow-up imaging that was negative for subsidence, disc migration, or significant motion restriction. None of the prostheses required revision surgery during this series. Most patients reported use of pain medication within 14 days of initial baseline evaluation $(87.8 \%)$. This number showed a significant decrease at 1 year (34.5\%, $P<.0001)$ and long-term follow-up (21.2\%, $P<.0001$ ) (Figure 3). At baseline, BP and LP were reported in $100 \%$ and $91 \%$ of patients, respectively. Significantly fewer patients reported either BP or LP at 1 year $(12.1 \%$ and $12.1 \%, P<$ $.0001)$ and long-term follow-up $(6.1 \%$ and $9.1 \%, P$ $<.0001) ; 59.3 \%$ of patients had a sensory deficit on neurological evaluation at baseline. This was reduced to $0 \%$ at 1 year and $12.5 \%$ at final follow-up. Clinical outcomes are detailed in Table 2.

\section{DISCUSSION}

The present study aimed to evaluate the shortterm, mid-term, and long-term clinical and radiologic outcomes of patients who underwent LTDR with the Activ-L disc replacement system. Additionally, we aimed to assess functional outcomes to examine if disc replacement surgery improved a patient's quality of life. Functional outcomes were measured using self-reporting from patients' ODI scores. Previous studies on the effectiveness of the Activ-L disc replacement system have also shown significant improvement in ODI scores. A study by Lu et $\mathrm{al}^{10}$ had a similar sample size to our study (32 patients) and obtained similar results in the setting of functional outcomes. These results were replicated in a retrospective controlled study determining clinical outcomes in LTDR versus anterior lumbar interbody fusion. ${ }^{11}$ The patients who underwent
Table 2. Clinical outcomes. Continuous variables shown as mean \pm standard deviation; categorical variables shown as $\mathrm{n}(\%)$.

\begin{tabular}{lc}
\hline Parameter & Value \\
\hline Average follow-up, y & $2.7 \pm 1.7$ \\
Oswestry Disability Index & \\
$\quad$ Baseline & $54.6 \pm 13.5$ \\
$\quad$ Final & $15.6 \pm 16.3$ \\
Sensory deficit* & $19(59.3)$ \\
$\quad$ Baseline & $4(12.5)$ \\
$\quad$ Final & \\
Back pain & $33(100)$ \\
$\quad$ Baseline & $2(6.1)$ \\
Final & \\
Leg pain & $30(91.0)$ \\
$\quad$ Baseline & $3(9.1)$ \\
$\quad$ Final & \\
Using pain medication & $29(87.8)$ \\
$\quad$ Baseline & $7(21.1)$ \\
Final &
\end{tabular}

${ }^{*}$ Total $\mathrm{N}=32$.

TDR with the Activ-L reported significantly lower ODI scores at all follow-up time points. Equivalent to results published by Lazennec et $\mathrm{al}^{12}$ and the aforementioned studies, our study participants showed a significant improvement in ODI. There was also a consistent decrease in ODI from baseline to final follow-up. This suggests that patients' functional outcomes not only improved rapidly (47.6\% decrease at 6 weeks) but also continued to improve throughout their clinical course. Participants' average ODI at final follow-up was lower than or comparable with previously published studies. $^{13-15}$

Given the recent interest in reducing exposure to and potential abuse of pain medications (especially narcotics), we found it imperative to examine changes in pain medication consumption following LTDR. Although many studies have investigated narcotic consumption following lumbar fusion, few studies have discussed pain medication use following lumbar disc replacement surgery. ${ }^{16}$ In an analysis by Aghayev et al, ${ }^{17}$ they noted a decreasing trend in non-steroidal anti-inflammatory drugs (NSAID), weak opiate, and strong opiate use from baseline to follow-up at 5 years. In a similar study published by Zigler et $\mathrm{al}^{18}$ patients' narcotic consumption decreased from $84 \%$ at baseline to $39 \%$ postoperatively at 24 -month follow-up. Our findings reflect the decrease in pain medication consumption at long-term follow-up seen in these studies. $^{16-18}$

An important metric in evaluating the success of lumbar replacement surgery is the incidence of postsurgical complications. Guyer et $\mathrm{al}^{13}$ reported 
an $11.8 \%$ reoperation rate in an investigational group who underwent Kineflex-L (SpinalMotion, Mountain View, California) disc replacement. In a meta-analysis conducted by Wei et al, ${ }^{19}$ they found an overall reoperation rate of $5.2 \%$ in patients who underwent LTDR among 1,525 participants in 5 randomized controlled trials. Although reoperation rates were low, none of the trials included in this analysis achieved a reoperation rate of $0 \%$. In the present study, there were no reoperations or revision surgeries documented at any point during clinical follow-up. It is important to note, however, in comparison with the previous studies our sample size was smaller. When examining reoperation rates, the difference in sample size must be taken into account. Although 33 patients represents a small sample, a study by Lu et $\mathrm{al}^{20}$ had a similar sized study population (35 patients) in which 2 patients required reoperation. We believe the reoperation rate in our present study is clinically significant when also considering the pain reduction, improved functional outcomes, and imaging studies observed in the reported patients.

The present study is a single-surgeon, singlecenter, small patient series, and so carries the associated biases. We feel that the small size of the sample included here is balanced by the relative novelty of the device investigated, as well as the long follow-up achieved in these patients, which demonstrates the durability of outcomes using the Activ-L system. Although these results are preliminary, a large prospective multicenter study would more powerfully demonstrate the efficacy of this device.

\section{CONCLUSIONS}

The Activ-L disc replacement system is safe and effective for treating single-level lumbar DDD. Patients reported significant improvement in functional outcomes, as evidenced by substantial reduction in ODI scores and significant decreases in pain medication consumption. Significantly fewer patients reported back and pain at long-term followup. Further investigation of the Activ-L system in larger populations is certainly warranted.

\section{REFERENCES}

1. Taher F, Essig D, Lebl DR, et al. Lumbar degenerative disc disease: current and future concepts of diagnosis and management. Adv Orthop. 2012;2012:7.

2. Clavel P, Ungureanu G, Catala I, Montes G, Malaga X, Rios M. Health-related quality of life in patients undergoing lumbar total disc replacement: a comparison with the general population. Clin Neurol Neurosurg. 2017;160:119-124.

3. Hoy D, Bain C, Williams G, et al. A systematic review of the global prevalence of low back pain. Arthritis Rheum. 2012;64(6):2028-2037.

4. Violante FS, Mattioli S, Bonfiglioli R. Chapter 21 - Lowback pain. In: Lotti M, Bleecker ML, eds. Handbook of Clinical Neurology. Vol 131. Amsterdam, Netherlands: Elsevier; 2015:397-410.

5. Ma VY, Chan L, Carruthers KJ. Incidence, prevalence, costs, and impact on disability of common conditions requiring rehabilitation in the United States: stroke, spinal cord injury, traumatic brain injury, multiple sclerosis, osteoarthritis, rheumatoid arthritis, limb loss, and back pain. Arch Phys Med Rehabil. 2014;95(5):986-995.e981.

6. Beatty $\mathrm{S}$. We need to talk about lumbar total disc replacement. Int J Spine Surg. 2018;12(2):201-240.

7. Hasz MW. Diagnostic testing for degenerative disc disease. Adv Orthop. 2012;2012:413913.

8. Aesculap, Inc. Activ-L artificial disc. https://www.aescu lapimplantsystems.com/activl. Accessed December 22, 2018.

9. Fairbank JC, Pynsent PB. The Oswestry Disability Index. Spine. 2000;25(22):2940-2952; discussion 2952.

10. Lu S, Kong C, Hai Y, et al. Retrospective study on effectiveness of active- $\mathrm{L}$ total disc replacement: clinical and radiographical results of 1 - to 3-year follow-up. Spine. 2015;40(7):E411-E417.

11. Mattei TA, Beer J, Teles AR, Rehman AA, Aldag J, Dinh D. Clinical outcomes of total disc replacement versus anterior lumbar interbody fusion for surgical treatment of lumbar degenerative disc disease. Global Spine J. 2017;7(5):452459.

12. Lazennec JY, Rakover JP, Rousseau MA. Five-year follow-up of clinical and radiological outcomes of LP-ESP elastomeric lumbar total disc replacement in active patients. Spine J. 2019;19(2):218-224.

13. Guyer RD, Pettine K, Roh JS, et al. Five-year follow-up of a prospective, randomized trial comparing two lumbar total disc replacements. Spine. 2016;41(1):3-8.

14. Van de Kelft E, Verguts L. Clinical outcome of monosegmental total disc replacement for lumbar disc disease with ball-and-socket prosthesis (Maverick): prospective study with four-year follow-up. World Neurosurg. 2012;78(3-4):355363.

15. Blumenthal S, McAfee PC, Guyer RD, et al. A prospective, randomized, multicenter Food and Drug Administration investigational device exemptions study of lumbar total disc replacement with the CHARITÉ ${ }^{\mathrm{TM}}$ artificial disc versus lumbar fusion: part I: evaluation of clinical outcomes. Spine. 2005;30(14):1565-1575.

16. Thavaneswaran $\mathrm{P}$, Vandepeer M. Lumbar artificial intervertebral disc replacement: a systematic review. $A N Z J$ Surg. 2014;84(3):121-127.

17. Aghayev E, Etter C, Bärlocher C, et al. Five-year results of lumbar disc prostheses in the SWISSspine registry. Eur Spine J. 2014;23(10):2114-2126.

18. Zigler J, Delamarter R, Spivak JM, et al. Results of the prospective, randomized, multicenter Food and Drug Administration investigational device exemption study of the ProDisc $^{\circledR}-\mathrm{L}$ total disc replacement versus circumferential fusion for 
the treatment of 1-level degenerative disc disease. Spine. 2007;32(11):1155-1162.

19. Wei J, Song Y, Sun L, Lv C. Comparison of artificial total disc replacement versus fusion for lumbar degenerative disc disease: a meta-analysis of randomized controlled trials. Int Orthop. 2013;37(7):1315-1325.

20. Lu S, Sun S, Kong C, et al. Long-term clinical results following Charite III lumbar total disc replacement. Spine J. 2018;18(6):917-925.

Disclosures and COI: Dr Wang declares the following financial interests/personal relationships, which may be considered as potential competing interests: royalty payments from DePuy-Synthes Spine, Inc, Children's Hospital of Los Angeles, Springer Publishing, and Quality Medical Publishing; consultant for DePuy-Synthes Spine, Inc, Stryker Spine, K2M, and Spineology; advisory board member for Vallum; stock in Spinicity and Innovative Surgical Devices; and grants from the Department of Defense. Drs Garcia and Wang declare the following financial interests/personal relationships, which may be considered as potential competing interests: consultant and royalties for Aesculap. The other authors received no funding for this study and report no conflicts of interest. This research did not receive any specific grant from funding agencies in the public, commercial, or notfor-profit sectors.

Corresponding Author: Michael Y. Wang, Lois Pope Life Center, Department of Neurological Surgery, 1095 NW 14th Terrace, Miami, FL 33136. Phone: (305) 243-3294; Fax: (305) 243-3337; Email: mwang2@med.miami.edu.

Published 11 November 2020

This manuscript is generously published free of charge by ISASS, the International Society for the Advancement of Spine Surgery. Copyright (C) 2020 ISASS. To see more or order reprints or permissions, see http://ijssurgery.com. 